\title{
Os limites entre a História e a Ficção
}

\author{
The limits between History and Fiction
}

\author{
Renata Geraissati Castro de Almeida \\ rgeraissati@gmail.com \\ Mestre em História \\ Universidade Federal de São Paulo. \\ Rua Doutor Armando Marcondes Machado, 43 - Vila Centenário \\ 03645-060 - São Paulo - SP \\ Brasil
}

\section{Resumo}

"O que fabrica o historiador quando 'faz história'?". Ao propor esta pergunta Certeau concluí que o historiador ao exercer seu ofício tem como resultado um produto, que tem imbricadas a presença de uma dimensão artística, que promove a ação do conteúdo sobre a forma, a consolidação da prática em um texto histórico. Ao propor um papel criador na prática do historiador, associado com um método de pesquisa documental, o autor mostra a História como um misto entre ciência e arte. O objetivo deste artigo é, portanto, compreender como estes debates entre história e ficção foram utilizados na produção historiográfica. Inegavelmente houve uma contribuição no sentido de tornar a todos os historiadores conscientes da poética da história, contudo, o estatuto das fontes continua mantido, não se pode deixar de considerar que o documento deve continuar a desempenhar um papel fundamental no fazer historiográfico, e que todo historiador ao criar sua interpretação, deve estar comprometido com o "princípio de realidade".

\section{Palavras-chave}

Historiografia; Narrativas; Ficção.

Abstract: "What makes the historian when 'makes history'?". In proposing this question Certeau concluded that the historian generate with his practice a product that has the presence of an artistic dimension, that promotes an action of the content through the form, consolidating the practice into a historic text. By proposing a creative role in the historian's practice, associated with a method of documentary research, the author shows history as a mixture of science and art. The purpose of this article is therefore to understand how these debates between history and fiction have been used in the production of some historians. Undeniably there was a contribution towards making all historians aware of the poetics of history, however, the status of sources still be maintained, the document should continue to play a key role in historiography, and that all historian in the process of to creating his interpretation, must be committed to the "reality principle."

\section{Keywords}

Historiography; Narratives; Fiction.

Recebido em: 21/10/2016

Aprovado em: 6/12/2016 
A História desde os anos de 1960 tem passado por uma intensificação de debates a respeito de sua epistemologia, contudo, é na primeira metade dos anos 70 que estas questões adquiriram maior visibilidade. Neste contexto, a historiografia trouxe à tona discussões metodológicas e teóricas, que versavam sobre a cientificidade da disciplina, o papel do historiador na produção do conhecimento histórico, e sua narrativa como um documento. A História deixou de ter em si mesma uma existência, passando a depender das escolhas da narrativa dos historiadores, consolidando seu papel ativo de autoridade para falar do passado.

Os primeiros esforços do campo que visaram compreender como se dava o processo da escrita e qual a relação desta com a verdade encontrou respostas nas obras de Paul Veyne em Como se Escreve a História (1971), Hayden White em Meta-história (1973) e Michel de Certeau em A Escrita da História (1975). As problemáticas levantadas por estes autores indicavam que os textos não eram análises objetivas das fontes a exemplo do que faziam os positivistas, mas sim uma construção narrativa. Contudo, como entender e analisar a produção desta escrita?

O historiador francês Paul Veyne propunha que a História era um romance real, isto é, uma narração de fatos reais tendo o homem como ator (VEYNE 1998). Assim como no romance o historiador efetua um enquadramento dos eventos, organizando-os, simplificando-os, o que denota que os eventos não são compreendidos em seu todo, mas sim lateralmente embasados em indícios. 0 francês, apesar de propor que os estudos históricos não recuperam o passado de fato como ele ocorreu, não deixa de corroborar que a História é o conhecimento a partir do documento, ainda que produza um relato lacunar.

Por sua vez, o historiador norte-americano Hayden White questionou o caráter científico da História, concentrando sua análise na produção dos discursos historiográficos. Sua obra Meta-História - a imaginação histórica do século XIX, publicada no ano de 1973, apontava que o discurso histórico possuía um conteúdo poético e linguístico, e a partir da análise da construção dos textos era possível compreender as principais formas de consciência histórica. Por meio da identificação nos textos de diferentes estilos estéticos e da recuperação dos elementos pré-figurativos era possível se obter um modo preciso de conhecimento histórico. Para White,

Nessa teoria trato o trabalho histórico como o que ele manifestadamente é: uma estrutura verbal na forma de um discurso narrativo em prosa. As histórias (e filosofias da história também) combinam certa quantidade de "dados", conceitos teóricos para explicar esses dados e uma estrutura narrativa que os apresente como um ícone de conjuntos de eventos presumivelmente ocorridos em tempos passados (WHITE 1995, p. 12).

Verifica-se que para White a análise das obras deveria concentrar-se em seus aspectos internos. Ao colocar a forma narrativa da escrita em uma posição central o norte-americano a revela como um artefato literário, desconsiderando que possamos com a História atingir o princípio de realidade, já que a mesma 
falha ao tentar reconstruir o passado por meio da evidência. Considerando que esta é um processo linguístico o que importa são as estratégias retóricas, metafóricas e ideológicas.

Já Michel de Certeau coloca em primeiro plano na análise historiográfica os historiadores ao ter como ponto de partida o que o mesmo fabrica quando "faz história" (CERTEAU 2006, p. 63). Em a Operação Historiográfica, Certeau considera o ato de escrever uma operação que é a combinação de "de um lugar social", de "práticas científicas" e de "uma escrita", sendo a escrita o momento da concretização das pesquisas dos historiadores em um produto. Por intermédio da pesquisa e escrita, o historiador transforma seus objetos de estudo e neste movimento opera uma transformação e consolida um produto (CERTEAU 2006, p. 80). Sobre este movimento Certeau destaca,

Poder-se-ia dizer que ela não mais parte de "raridades" (restos do passado) para chegar a uma síntese (compreensão presente), mas que parte de uma formalização (um sistema presente) para dar lugar aos "restos" (indícios de limites e, portanto um passado que é produto do trabalho) (CERTEAU 2006, p. 86).

Ao colocar a escrita como uma das três partes da operação historiográfica, Certeau indica a relevância que esta possui no ofício do historiador. A importância deste ato não se limita apenas ao conteúdo que esta traz em si, mas também à forma de sua produção, pois por meio desta podemos compreender qual seu contexto de produção e qual o lugar social que seu autor ocupa. No processo de gerar um produto, Certeau já indica a presença da dimensão artística no trabalho do historiador, mostrando que nesta operação o aspecto ficcional está inserido. Ao propor um papel criador no ofício do historiador, associado com um método de pesquisa documental, o autor mostra a História como um misto entre ciência e arte.

As reflexões destes autores repercutiram na produção dos historiadores contemporâneos e da geração posterior, e propiciaram que aspectos tais como cientificidade e veracidade da história se tornassem os principais elementos no embate dos últimos 50 anos. A dimensão dada ao papel criador na operação historiográfica e em que medida ele o produto gerado pela narrativa concebe a realidade do passado se tornou o ponto de divergência entre os historiadores da usualmente chamada linguistic turn. No entanto, além das discussões no interior deste grupo, suas obras circularam suscitando debates e críticas com outros historiadores partidários da micro-história e dos Annales.

\section{A Virada Linguística}

Dentro deste grupo, muitas vezes categorizado uniformemente como pósmoderno temos uma enorme diversidade de concepções. A historiadora norteamericana Gabrielle Spiegel desde os anos 1990 tem analisado a produção destes autores e considerado o impacto de suas propostas para revisitar antigos debates. A respeito de uma coerência interna destes autores, Spiegel relata que "é difícil imaginar que não exista uma ideia compartilhada sobre o 
que queremos dizer com esse termo [...] podemos identificar uma série de diferentes concepções, mostrando que as posições intelectuais expressas por estes são heterogêneas, principalmente na dimensão entre ficção e realidade" ${ }^{\prime 1}$ (SPIEGEL 2007, p. 9). Retomando La Capra a autora corrobora que sua classificação em categorias como pós-estruturalismo e pós-modernismo são menos importantes que o resultado que implicaram em uma mudança nas concepções e no fazer histórico.

Visando mapear a produção do saber histórico a partir das perspectivas deste grupo o historiador inglês Alun Munslow escreve em 1997 o livro Desconstruindo a História. Nele o autor tem como objetivo analisar o limite da história em recuperar e apresentar com precisão o conteúdo do passado por meio da narrativa, uma vez que essa não é um meio neutro para descrever e explicar a realidade passada, mas sim um elemento externo que impõe um formato ao passado que não lhe é próprio, algo que remete à problemática da linguagem enquanto constitutiva da realidade ou apenas reflexo dela.

O inglês considera que a produção destes historiadores pode ser subdividida em três categorias que coexistem contemporaneamente, construcionistas, reconstrucionistas e desconstrucionistas. Posicionando-se dentro da categoria dos desconstrucionistas, o autor propõe que devemos revisar não apenas o método histórico, mas também seus fundamentos, pois, a história só é genuína quando a entendemos como uma criação e não como um empreendimento empirista objetivo. O fazer historiográfico seria o resultado de um trabalho de base linguística de transformação do passado por meio da narrativa, no ofício de reunir, selecionar e usar informações para a elaboração de um texto coerente. O historiador se por meio da imaginação figurativa impõe ao passado um enredo e o preenche com significados para constituir um presente, logo, não há correspondência entre o passado e sua representação narrativa (MELLO 2010, p. 232-238).

Logo, temos que o desconstrucionismo não aceita correspondência entre a evidência e a verdade histórica, uma vez que a construção de significados se dá pela estrutura narrativa e não por informações inerentes às fontes. Portanto, enquanto reconstrucionistas e desconstrucionistas aceitam a evidência como prova de um contexto que aconteceu no passado, por sua vez os descontrucionistas creem que ela sinaliza apenas possíveis realidades de interpretações. Para desconstrucionistas, o conhecimento não é descoberto e sim criado pela linguagem, portanto nada é isento da formatação do historiador,

\footnotetext{
${ }^{1}$ Sobre a distinção entre ficção e história Hayden White pontua que grande parte dos historiadores acredita que "o que distingue os enredos "históricos" dos "ficcionais" é, antes de tudo, o conteúdo, não a forma. O conteúdo dos enredos históricos é o evento real, o que realmente aconteceu, e não o imaginário, inventado pelo narrador. Donde se infere que a forma com que os eventos históricos se apresentam a um possível narrador não é construída, e sim encontrada" (WHITE 2011, p. 441). Contudo, para o autor a questão não se resolve com o que é proposto nesta passagem, posto que é possível produzir textos imaginários sobre acontecimentos reais, não sendo em decorrência deste aspecto menos verdadeiros, logo, a distinção entre real e imaginário pertenceria tanto à ordem dos acontecimentos, quanto à dos discursos. Jean-Marie Schaeffer pontua que "um quadro figurativo seria uma ficção pelo simples fato de que ele é sempre uma imitação (uma representação análoga) da realidade", portanto, em qualquer construção discursiva estaríamos operando e criando uma imitação, dada a incapacidade de recuperar algo como realmente ocorreu (SCHAEFFER 1999, p. 17). Para o autor, existem três condições básicas que fundamentam o estatuto ficcional: a similitude, a imitação e a fantasia lúdica.
} 
comprometendo assim os critérios de objetividade. A evidência, a partir dessa perspectiva, não reflete o passado, mas serve ao historiador na composição de sua narrativa. Inserido na última categoria proposta por Munslow, Hayden White explicita seu ponto de vista a respeito da construção das narrativas como composições de fatos presentes nas fontes:

Muitos historiadores continuam a tratar os seus fatos como se fossem dados e se recusam a reconhecer, diferentemente da maioria dos cientistas, que os fatos, mais que descobertos, são elaborados pelos tipos de pergunta que o pesquisador faz acerca dos eventos que tem diante de si (WHITE 2001, p. 56).

Entre os rastros do passado e sua representação no presente, existe uma série de elementos extratextuais tais como, a ideologia, a linguagem, as preferências pessoais e as discussões historiográficas, que impossibilitam uma imparcialidade e objetividade. Contudo, para o método formalista proposto por White são relevantes apenas os aspectos internos às obras, como enredo, argumento e ideologia. Portanto, a análise da vida pessoal do escritor, seu contexto social específico e seus escritos passados não são necessários (WHITE 2001). Sua vantagem interpretativa é mostrar que a linguagem cria significados, sejam eles criados conscientemente ou não pelo historiador.

Munslow, contudo, ressalta que a abordagem desconstrucionista não é antirreferencialista, mas ela nos adverte sobre os limites que a evidência exerce no trabalho do historiador. A evidência não emite os significados do passado, nem permite que qualquer coisa seja escrita sobre ele. Muitos autores, entre eles Roland Barthes, consideraram que a história se propõe a criar uma realidade externa ao discurso, o que dá uma "ilusão de realidade" ao texto, isto é, o historiador ao trabalhar com fontes - elas também textos - reconstrói algo que nunca existiu. Algo semelhante ao que acredita Ricouer, que diferentemente de Certeau não separa os momentos da operação historiográfica, pois todos os objetos de análise são textuais, e quando não estamos escrevendo estamos lidando com outros textos. Os autores críticos às análises do linguistic turn utilizam este aspecto autocentrado como principal ponto de defasagem desta teoria. Um desses é Dosse, para quem aqueles autores reduzem a história a uma atividade de interpretação de textos fechados em si mesmos (DELACROIX 2012, p. 341).

Munslow destaca os princípios teóricos de Hayden White "provavelmente o mais radical desenvolvimento na metodologia histórica nos últimos trinta anos" (MUNSLOW 2009, p. 187). Como principal expoente da categoria dos desconstrucionistas, alguns pressupostos whiteanos são relevantes para compreendermos o porquê Muslow o considera com uma proposta de análise radical. Para o norte-americano os eventos em si não trazem consigo uma dada história, isto é, os acontecimentos não são inerentemente trágicos, cômicos, satíricos, não há uma forma de escrita dos acontecimentos a ser descoberta. É o historiador que irá organizar as informações em uma narrativa dando-lhe um significado e lhe impondo um enredo, de acordo com um dos tropos metáfora, metonímia, sinédoque e ironia. Esse significado é, em grande medida, uma 
consequência do tropo escolhido e não das próprias fontes. Esses dois pressupostos sustentam as afirmações de White, e as apropriações de Munslow, sobre o caráter imposicionalista do historiador, por meio da linguagem, na construção das narrativas sobre o passado e, consequentemente, de seus significados.

Em última instância, os estudos desconstrucionistas indagam se "o que se coloca em questão não é como o passado deve ser investigado e explicado, mas se o passado deve ao menos ser estudado" (WHITE 2001, p. 50). O fardo da história é lidar com uma disciplina que não faz sentido para seu presente (WHITE 2001, p. 52), é a perda da consciência histórica e a dúvida com relação ao seu valor.

\section{Ficção e o Princípio de Realidade}

O legado deste debate para a atual historiografia está em uma inegável modificação nas concepções sobre o que é a ciência para a história. François Dosse propõe que a partir da década de 1970 os modelos cientificistas de história passaram por questionamentos, propiciando o surgimento de novas perspectivas. Neste cenário devemos entender a história não como "um saber cumulativo, mas como a coexistência e a sucessão de várias "linguagens teóricas de descrição" que definem uma pluralidade teórica", destacando-se tanto a linguistic turn, como outra corrente historiográfica que buscou dar responder os mesmos problemas e que ficou conhecida como micro-história (DELACROIX 2012, p. 329).

Um dos representantes da última, Carlo Ginzburg ${ }^{2}$ aponta que as modificações pelas quais passa a historiografia são decorrência do fracasso da aplicação da ciência galileana para as ciências sociais. O italiano concebe a história relacionada ao paradigma indiciário, que versa sobre o individual, possibilitando com a modificação de escala tornar possível perceber fatos relevantes negligenciados em contextos generalizadores. Portanto, a disciplina viveria em um dilema: ou continua a seguir o modelo galileano e assume um estatuto científico forte, obtendo resultados de pouca relevância ou então assume um estatuto científico frágil, porém consegue atingir resultados relevantes. Em outras palavras, ou se sacrifica o individual a generalizações ou se elabora um novo paradigma sobre conhecimento científico no individual.

Ao escolher como paradigma o método indiciário, Ginzburg, se propõe a produzir o conhecimento histórico com base nos rastros e a sintetizá-lo em sua escrita, que é também uma narração. Ao destacar o papel dos rastros, é retomado um dos fundamentos da historiografia, que se centra em torno da prova, dado que por meio da documentação o historiador cria suas hipóteses e possibilidades de interpretação.

Em momentos diferentes de sua trajetória o italiano mostra sua preocupação com esta questão, como demonstra em sua entrevista a Maria Lúcia Pallares propondo que "trabalhar em ambos os lados deve ser central

2 Texto original de 1980. GINZBURG, Carlo. Signes, traces, pistes Racines d'un paradigme de I'indice. Le Débat, 1980. v. 6. 
para os historiadores. Ter um profundo desrespeito pela mentira e, ao mesmo tempo, um profundo respeito pelas crenças, pelos sentimentos, me parece essencial (GINZBURG 2000, p. 281). Portanto, ainda que o estatuto dos documentos tenha se modificado, e que ocorra um ponto de contato entre discurso literário e histórico, não significa que as distinções entre ficção e história tenham sido sublimadas,

Termos como "ficção" ou "possibilidade" não devem induzir a erro. A questão da prova permanece mais que nunca no cerne da pesquisa histórica, mas seu estatuto é inevitavelmente modificado no momento em que são enfrentados temas diferentes em relação ao passado, com a ajuda de uma documentação que também é diferente. [...] Hoje, ao contrário, o entrelaçamento de verdades e possibilidades, assim como a discussão de hipóteses de pesquisa contrastantes, em alternância com páginas de evocação histórica, não desconcertam mais (GINZBURG 2000, p. 333-334).

Ao dialogar com os partidários da virada linguística, Ginzburg propõe que aqueles ao abordarem a questão da narrativa utilizam-se de porções "historiográficas individualizadas, geralmente fora do contexto ignorando o trabalho preparatório de pesquisa que as tornara possíveis" (GINZBURG 2007, p. 320). Por meio de atitudes relativistas anulam distinção entre ficção e história, entre narrações fantásticas e com pretensão de verdade,

Uma verificação das pretensões de verdade inerentes às narrações historiográficas como tais, implicaria a discussão dos problemas concretos ligados às fontes e às técnicas da pesquisa, a que os historiadores tinham se proposto em seu trabalho. Se esses elementos são desdenhados, como faz White, a historiografia se configura como puro e simples documento ideológico (GINZBURG 2007, p. 327).

$\mathrm{Na}$ produção historiográfica de White a referencialidade do discurso pautada na seleção documental não é abordada, se tornando o elemento que propiciou a crítica de outros historiadores. Em decorrência desta forma de análise intratextual White foi alvo, nos anos de 1990, de uma série de questionamentos por parte de Roger Chartier, que se negava a acreditar em uma diluição dos conflitos como unicamente frutos da linguagem. Para o francês esta falta de clareza entre história e ficção, ocasionou um abandono de toda intenção de verdade na produção historiográfica, propiciando um cenário maléfico que ignora os rastros deixados pelo passado (CHARTIER 2002). Para o autor é inconcebível pensar a história e os historiadores se diferenciando unicamente por aspectos formais internos ao discurso (CHARTIER 2002, p. 111) e não por sua menor ou maior pertinência em dar conta da realidade passada que é seu objeto. ${ }^{3}$ Para ele,

Fazer a história da história não seria compreender como, em cada configuração histórica dada, os historiadores colocam em ação técnicas de

3 Para White a História não pode ter uma comprovação rigorosa, portanto a operação sobre as fontes tem função ritual (MARQUEZ 2010). 
pesquisa e procedimentos críticos que justamente dão a seus discursos, de maneira desigual, essa "honestidade" e essa objetividade? (CHARTIER 2002, p. 116).

Sua crítica a White evidencia que se a história produz um conhecimento que é idêntico ao gerado pela ficção, então como podemos considerar a questão da produção do corpus documental? Seria então a operação historiográfica um desperdício de tempo?

O mesmo desconforto com relação ao esvaziamento da distinção entre ficção e realidade é expresso por Art Spiegelman, que após ter sua obra Maus colocada na categoria de ficção, rebate com tom de ironia, que não teria passado por árduos anos de pesquisa para fundamentar o livro se soubesse que seria categorizado como ficção. Para Dominick La Capra a obra de Spiegelman, que é tanto "uma obra completa de memória e o duelo entre reconstrução histórica auto-etnográfica e arte" (LACAPRA 2009, p. 205) são relevantes para se problematizar esta distinção entre ficção e não ficção, uma vez que estas categorias binárias não dão conta das diversidades que permeiam a escrita.

Dentre os problemas levantados na distinção entre ficção/realidade se coloca o problema da validade dos testemunhos. Helmut Galle destaca que são categorias híbridas entre ficção e teoria literária (GALLE 2005, p. 3; p. 83), pois são a realidade experimentada pelo autor que é idêntico ao protagonista, e por seu conteúdo parecem novela, mas pertencem à história. Uma vez que são fruto da experiência, os testemunhos só podem ser escritos por pessoas que tiveram a experiência de viver neste passado, pois para poder ter as recordações deste passado é necessário que a pessoa tenha vivido neste contexto. Se a pessoa não viveu esta experiência o que ela expressa é outra coisa, que não um relato (GALLE 2005, p. 399).

De acordo com esta ideia, o autor de "Testimonio Ficcional, factual y falsificado" discorda de White na afirmação daquele de que não são os fatos que determinam o passado, mas sim as estruturas narrativas. Pois os testemunhos mostram que a factualidade e a referencialidade do texto nem sempre são internas, mas às vezes vem de seu contexto social de produção e se ligam a autoria de quem faz a afirmação, uma vez que esta afirmação se vincula a sua realidade vivida. Galle também destaca que apesar do que acreditava Roland Barthes, que na sociedade atual não fazia mais sentido em distinguir fiç̧ão e realidade, ambas continuam muito presentes nos interesses contemporâneos, gerando até processos judiciais (GALLE 2005), como mostrado nos exemplos de seu texto.

A questão da experiência possui uma enorme centralidade, na produção de Spiegel, assim como na de outro historiador alemão, Reinhart Koselleck. Ao abordar o revisionismo que desde os anos 70 questionava a legitimidade da representação do passado, dizendo que a realidade da ação (passado) é diferente de sua busca (história), Spiegel retoma Certeau e critica o fato desses trabalhos estarem apenas tem se preocupando com a última etapa do ofício do historiador, o processo a "escrita". A autora inserida na tradição historiográfica 
anglo-saxã também destaca o documento como fundamental no processo de escrita da história,

Com certeza, a muito nós nos distanciamos de perseguir o "nobre sonho" de uma objetiva, investigação histórica baseada no positivismo, como Peter Novick habilidosamente demonstrou, não é mais compartilhada pela maioria dos historiadores, entretanto continuamos a insistir e respeitar a base empírica em toda investigação histórica. [...] Nós ainda acreditamos na função do corpo documental na pesquisa histórica [...] (SPIEGEL 2007, p. 3).

Para Spiegel não podemos deixar de considerar o lugar e a prática, pois além dos aspectos formais da escrita, a experiência do autor também influencia neste processo, contradizendo o que muitos pós-modernistas chamaram de a "morte do autor". Algo semelhante é ressaltado por Koselleck que apresenta a História como fruto da relação entre escrita, experiência e método, mostrando que após 1780 , se convencionou que a ela é tanto a realidade experimentada como o conhecimento científico e cognitivo produzido pela consciência social e individual. Para ele as mudanças metodológicas pelas quais passou a história são resultado de uma mudança de experiência via conhecimento sociológico, pois mudanças sociais e políticas geram inovações metodológicas. Em sua concepção o método é reflexo da experiência, pois é a partir de nossa experiência que analisamos a experiência alheia. Esta analise não é feita de forma aleatória, mas sim pautada em elementos concretos que dão credibilidade a noção de realidade do historiador. Para Koselleck

210 história é a transposição do conhecimento em narrativa para assim obtermos conhecimento (KOSELLECK 2002, p. 58).

Spiegel parece concordar com o fato de que é a mudança da experiência vivida que gera uma mudança metodológica. Para ela podemos atribuir essa nova historiografia entre outros fatores ao Holocausto, pois este evento extremo provocou uma mudança na experiência que levou ao questionamento sobre o que era possível dizer sobre o passado. Segundo a autora este foi um momentoproblema na relação entre res et verba (fato e palavra). Estas novas interpretações fundadas na ruptura (SPIEGEL 2007, p. 10) marcam profundamente os escritos de diversos historiadores. Veremos, portanto, que "para aqueles que sobreviveram e para os que vieram depois, o Holocausto parecia exceder a capacidade de representação da realidade" (SPIEGEL 2007, p. 11).

\section{Considerações finais}

A contribuição de autores como Veyne, Certeau e White, e as futuras apropriações por Spiegel e Munslow, dentre outros que abordam a questão da escrita da história não pode ser minimizada. A partir das questões inicialmente propostas sobre o texto ou como um produto permeado de intencionalidades de seu autor, ou como uma construção do passado por intermédio da narrativa, possibilitou que os historiadores repensassem seu ofício e seu fazer historiográfico.

Portanto, autores tais como Ginzburg, Chartier e Dosse, ainda que contrários a diversos postulados destas teorias, buscaram se familiarizar com seus debates 
para assim, terem fundamentos em suas críticas, defendendo assim um método e um rigor na produção historiográfica. Ginzburg destaca a relevância destas análises, dizendo que,

Até muito tempo atrás, a maioria dos historiadores enxergava uma nítida incompatibilidade entre a acentuação do caráter científico da historiografia (tendencialmente assimilada às ciências sociais) e o reconhecimento de sua dimensão literária. Hoje, ao contrário, esse reconhecimento é estendido cada vez mais a obras de antropologia ou de sociologia, sem que isso implique necessariamente, de quem o formula, um juízo negativo (GINZBURG 2007, p. 326).

Vemos que discussões iniciadas por Certeau como "lugar, prática e escrita" foram incorporadas como constitutivas da historiografia,

Acredito que há coisas que podem ser provadas, que há um lado objetivo a ser encontrado, que pode ser aceito mesmo por pessoas que trabalham com pressupostos diferentes, no entanto, também reconheço que os historiadores são pessoas que falam a partir de um lugar [...], portanto, o conhecimento que produzem também é localizado (GINZBURG 2000, p. 298).

Portanto é inegável que houve uma contribuição no sentido de tornar a todos os historiadores conscientes da poética da história. Porém não se pode deixar de ter em vista que o documento deve continuar a desempenhar um papel fundamental no fazer historiográfico, e que todo historiador ao criar sua interpretação, que é um misto de ciência e arte, deve estar comprometido com o "princípio de realidade".

Dosse mostra que nos anos 90, visando manter a autonomia da História e reafirmá-la contra sua a redução à ficção, às ficções negacionistas ${ }^{4}$, às derivas memoriais, às instrumentalizações sociais e políticas da história, houve um consenso mínimo entre os historiadores sobre a intenção de verdade. A noção de prova continua como parte preponderante do trabalho do historiador, que ao construir suas interpretações tem a obrigação de fornecer os dados que permitem dar credibilidade a mesma, e por meio do caráter de prova o historiador coloca sua escrita dentro do campo da história e não da ficção (DELACROIX 2012, p. 383).

Por fim, temos que destacar que as produções da linguistic turn até o presente momento se centraram em obras de reflexão teórica sobre o fazer historiográfico, porém ainda não elaboraram obras de História, isto é, elas até então se preocuparam em analisar como construir a produção do conhecimento histórico e não em como investigá-lo/abordá-lo. Portanto, para a maioria dos historiadores, por não ter uma obra de referência, parece ser impossível aplicar estes métodos na construção do conhecimento histórico.

\footnotetext{
${ }^{4}$ Para White os negacionistas não realizam uma reescrita da história nos moldes formalistas, pois seguem metodologicamente os modelos históricos convencionais, isto é, crítica das fontes. WHITE, Haden. A response to Professor Chartier's four questions. Storia dela Storiografia, 27, 1995.
} 


\section{Referências bibliográficas}

CERTEAU, Michel de. A operação historiográfica. In:

A escrita da

história. Rio de Janeiro: Forense Universitária, 2006 [1975].

CHARTIER, Roger. Figuras retóricas e representações históricas (Quatro questões a Hayden White) [1993]. In:

À beira da falésia. A história entre certezas e inquietude. Porto Alegre: Ed. Universidade; UFRGS, 2002.

DELACROIX, Chistian; DOSSE, François e GARCIA, Patrick. "Uma crise da História? (as décadas de 1980-1990). In: Correntes históricas na França (séculos XIX e XX). Rio de Janeiro: Ed. da FGV; São Paulo: Ed. da Unesp, 2012 [2005].

GALLE, Helmut. Testimonio ficcional, factual y falsificado. Qué enseñan los casos de recepción equivocada de la literatura sobre el Holocausto. In: CRUZ, Manuel y BRAUER, Daniel (Comp.). La comprensión del pasado. Escritos sobre la filosofía de la historia. Barcelona: Herder, 2005.

GINZBURG, Carlo. [Entrevista]. In: PALLARES-BURKE, Maria Lúcia Garcia. As muitas faces da história. Nove entrevistas. São Paulo: Ed. Unesp, 2000. . Apêndice - Provas e possibilidades (Posfácio a Natalie Zemon Davis, O retorno de Martin Guerre) [1984]. In: O fio e os rastros. Verdadeiro, falso, fictício. São Paulo: Companhia das Letras, 2007. .Unus testis - O extermínio dos judeus e o princípio de realidade [1990, 2005]. In: O fio e os rastros. Verdadeiro, falso, fictício. São Paulo: Companhia das Letras, 2007.

HOBSBAWM, Eric. A volta da narrativa [1980]. In: HOBSBAWM, Eric. Sobre história: ensaios. São Paulo: Companhia das Letras, 1998.

LACAPRA, Dominick. "Fue la noche después de la Navidad": Maus, de Art Spiegelman [1998]. In: Historia y memoria después de

Auschwitz. Buenos Aires: Prometeo, 2009.

KOSELLECK, Reinhart. Transformations of experience and methodological change. A historical-anthropological essay. In: The practice of conceptual history. Timing history, spacing concepts. Stanford: Stanford UP, 2002.

MARQUEZ, R. O. A teoria tropológica do discurso historiográfico: narrativa, descrição, evento, fato e ficção'. In: I Congresso Internacional do Curso de História de Jataí e 7 semena de Letras. Anais... Jataí, 2010.

MELLO, Ricardo Marques de. Um desconstrucionista desconstruindo a história. Revista História da Historiografia, Ouro Preto. n. 5, p.232-238, 2010.

MUNSLOW, Alun. Desconstruindo a história. Petrópolis: Vozes, 2009 [1997].

VEYNE, PAUL. Como se escreve a história.Brasília: Editora Universidade de Brasília, 1998 [1971]. 
SCHAEFFER, Jean-Marie. Porquoi la ficcion? Paris: Éditions Seuil, 1999.

SOUZA, Adriana Barreto de. Biografia e Escrita da História: reflexões preliminares sobre relações sociais e de poder. Rev. Univ. Rural, Sér. Ciências Humanas, v. 29, n. 1, p. 27-36, 2007.

SPIEGEL, Gabrielle M. Revising the past / Revisiting the present: how change happens in historiography. History \& Theory, v. 46, 1-19, 2007.

STONE, Lawrence. O retorno da narrativa: reflexões sobre uma nova velha história [1979]. In: NOVAIS, Fernando A.; SILVA, Rogerio Forastieri da (Org.). Nova história em perspectiva: Debates. São Paulo: CosacNaify, 2013. v. 2.

WHITE, Hayden. Meta-história. A imaginação histórica do século XIX. São Paulo: Edusp, 1995 [1973].

A response to Professor Chartier's four questions. Storia dela Storiografia, v. 27, 1995.

.Trópicos do discurso. Ensaios sobre a crítica da cultura. São Paulo: Edusp, 2001 [1978].

. Enredo e verdade na escrita da história [1990\}. In: MALERBA, Jurandir (Org.). A história escrita. Teoria e história da historiografia. São Paulo: Contexto, 2006.

. A questão da narrativa na teoria histórica contemporânea [1987]. In: NOVAIS, Fernando A.; SILVA, Rogerio Forastieri da (Org.). Nova história em perspectiva. Propostas e desdobramentos. São Paulo: CosacNaify, 2011. v. 1. 